\title{
Soluble Human IL-1 Receptor Type 2 Inhibits Ectopic Endometrial Tissue Implantation and Growth
}

\author{
Identification of a Novel Potential Target for Endometriosis \\ Treatment
}

Khaled Khoufache, ${ }^{*}$ Patrick Kibangou Bondza, ${ }^{*}$ Noria Harir, ${ }^{*}$ Marleen Daris, ${ }^{\dagger}$ Mathieu Leboeuf, ${ }^{\dagger}$ Jacques Mailloux, ${ }^{\dagger}$ Madeleine Lemyre, ${ }^{\dagger}$ Warren Foster, ${ }^{\ddagger}$ and Ali Akoum ${ }^{\star \dagger}$

From the Laboratory of Reproductive Endocrinology, Research Center, Hôpital Saint-François d'Assise, Centre Hospitalier Universitaire de Québec, Quebec City, Quebec; the Department of Obstetrics and Gynecology, ${ }^{\dagger}$ Faculty of Medicine, Laval University, Québec City, Québec; and the Department of Obstetrics \& Gynecology, McMaster University, Hamilton, Ontario, Canada

Endometriosis is often associated with a chronic pelvic immuno-inflammatory process, which is closely related to disease pathogenesis and major symptoms. Our studies led to the detection of a marked imbalance between IL-1 and its natural inhibitor IL-1 receptor type 2 (IL1R2) in women with endometriosis. This points to a deficiency in the local control of IL-1 that, in view of the cytokine's elevated levels and potent proinflammatory, angiogenic, and growth-promoting effects, may contribute to endometriosis development. Using an in vivo model in which human endometrial tissue was inoculated into nude mice and left to establish before any further treatment, our data showed that SIL1R2 interferes with the capability of endometrial tissue to invade, grow, disseminate, and stimulate angiogenesis into the host tissue. sIL1R2 significantly down-regulated the expression of major cell adhesion receptors ( $\alpha \mathrm{v}$ and $\beta 3$ integrins), matrix metalloproteinases (MMP-2 and -9), and vascular endothelial cell growth factor. Interestingly, treatment with sILR2 $(5 \mu \mathrm{g} / \mathrm{kg})$ led to a concomitant upregulation of matrix metalloproteinases natural inhibitors (TIMP1 and TIMP2) and down-regulation of BclII, a potent anti-apoptotic protein. This creates an imbalance between pro- and anti-proteolytic and apoptotic factors and may further contribute to IL1R2 growth-inhibitory effects. This study pro- vides evidence that SIL1R2 alters ectopic endometrial tissue growth, remodeling, and survival in vivo and may represent an interesting potential therapeutic tool. (Am J Pathol 2012, 181:1197-1205; http://dx. doi.org/10.1016/j.ajpath.2012.06.022)

Endometriosis is a serious gynecological pathologic condition and a major public health concern in view of its physical, psychological, and socioeconomic impacts. This disease affects $6 \%$ to $10 \%$ of reproductive-aged women, $50 \%$ to $60 \%$ of teenage girls with pelvic pain, and up to $50 \%$ of women with infertility. ${ }^{1,2}$ Endometriosis is estrogen dependent; however, several risk factors are thought to contribute to the pathogenesis of the disease. Abundant menstrual reflux and early menarche, ${ }^{3}$ genetic and environmental factors, ${ }^{4-7}$ hormonal dysfunctions, ${ }^{8}$ and impaired immune response have been suggested. 9,10 The most predominant hypothesis defines endometriosis as an abnormal implantation of endometrial tissue outside the uterus, mainly in the peritoneal cavity. ${ }^{11}$ This is supported by a growing body of evidence corroborating our first data and showing the intrinsic capability of endometrial tissue to invade, implant, and grow into the host tissue, and a significant contribution of immune factors to the development of endometriosis and its major clinical symptoms. ${ }^{10,12}$ Endometriosis is often associated with a chronic pelvic immunoinflammatory reaction. ${ }^{1}$ Autoantibodies nonspecific or specific to endometrial antigens have been found in the peritoneal fluid of patients along with an increased recruitment of proinflam-

Supported by a grant from the Canadian Institutes for Health Research (MOP-93716 to A.A). A.A. is a Chercheur-Boursier National of the Fonds de la Recherche en Santé du Québec (FRSQ). K.K., N.H., and P.B. were supported by a Wyeth-Ayerst CIHR/R\&D Fellowship.

Accepted for publication June 26, 2012.

Address reprint requests to Ali Akoum, Ph.D., Hôpital Saint-François d'Assise, 10, rue de l'Espinay, Local D0-711, Québec (Québec), Canada G1L 3L5. E-mail: ali.akoum@crsfa.ulaval.ca. 
matory cells, especially activated macrophages, and higher levels of reactive oxygen species, proteolysis enzymes, prostaglandins, and proinflammatory cytokines. $^{10,13-17}$

$\mathrm{IL}-1$ is a major proinflammatory cytokine that exerts its biological effects via the IL-1 receptor type 1 (IL1R1), the signaling receptor. IL-1 is regulated by IL-1 receptor antagonist (IL1RA) by competing for binding to ILR1. This control system is consolidated by another potent, specific, and natural IL-1 inhibitor, IL-1 receptor type 2 (IL1R2). This decoy receptor has no signaling properties. It instead counterregulates IL-1 signaling by sequestrating active and inactive IL-1, thereby restricting the cytokine's bioavailability and effects. Interestingly, both the membrane-bound receptor and the soluble form (sIL1R2), which results from a proteolytic cleavage form IL1R2 extracellular domain, can bind to and capture IL1. ${ }^{18-20}$

Our and other recent studies have led to the detection of an imbalance between IL-1 and sIL1R2 in the peritoneal fluid of patients with endometriosis, where a significant decrease in the levels of IL1R2 and a concomitant increase in those of IL-1 were noted ${ }^{13,21}$ This was quite obvious in initial endometriosis stages and is consistent with the marked down-regulation of IL1R2 protein and mRNA expression in the earliest and most active endometriotic lesions. ${ }^{22,23}$ These findings point to endometriosis-associated major defects in local IL-1 counterregulatory mechanisms, which, considering IL-1 proinflammatory, remodeling, angiogenic, and growth-promoting effects, may play an important role in the establishment and development of endometriosis.

Based on the above-reported evidence, we undertook an in vivo study to investigate the effects of an intraperitoneal administration of sIL1R2 on endometriosis progression using a murine model of endometriosis.

\section{Materials and Methods}

\section{Subjects and Tissue Handling}

Women who were included in this study provided informed consent for a research protocol approved by Saint-François d'Assise Hospital ethics committee. Endometrial tissue was collected using a Pipelle de Cornier (Prodimed, Neuilly-en-Thelle, France) during the proliferative phase (day 2 to day 13 ) of the menstrual cycle from 10 healthy, normally cycling women (mean \pm SD age, $36.2 \pm 5.2$ years) who were undergoing laparoscopy for benign conditions, did not have endometriosis, and were not receiving anti-inflammatory or hormonal medication for at least 3 months before surgery. A sample of each tissue was kept at $-80^{\circ} \mathrm{C}$ for histological confirmation of the menstrual phase. ${ }^{24}$ The remaining tissue, destined for the in vivo studies, was immediately washed in PBS, dissected into small $\left(1 \mathrm{~mm}^{3}\right)$ cubes, and labeled with a fluorescent tracker, carboxyfluorescein diacetate, succinimidyl ester (CFDA-SE) $\left(8.10^{-6} \mathrm{M}\right.$ in PBS) (Invitrogen. Burlington, ON, Canada). ${ }^{25}$ Tissue labeling was confirmed by fluorescence stereomicroscopy.

\section{Establishment of Endometrial Tissue Implants in} Nude Mice

The protocol was approved by the committee of animal protection of Laval University. Five- to 7-week-old female athymic Nude-Foxn1nu mice (Harlan Laboratories, Indianapolis, IN) were used after a 1-week acclimatization period. Mice were housed under laminar-flow filtered hoods at $28^{\circ} \mathrm{C}$ with a $12: 12$-hour light-dark cycle. Housing materials, food, and water were sterilized before use. Animals were given buprenorphine (1.68 $\mathrm{g}$ per mouse) by intradermal injection for analgesia, then anesthetized with a mixture of oxygen (1.5: I) and isoflurane (3\% to 4\%) (Abbot Laboratories, Saint-Laurent, Quebec, Canada). A small (1 cm) cutaneous and peritoneal incision was made in a sterile environment, and $0.1 \mathrm{~mL}$ of PBS containing 13 CFDA-labeled endometrial tissue fragments (Figure 1, A and B) was injected into the peritoneal cavity using a micropipette. The incision was closed with Coated NB (polyglactin 910) sutures (Ethicon Johnson \& Johnson, Markham, ON, Canada) for the peritoneal tissue and MikRon autoclip $9 \mathrm{~mm}$ (Clay Adam Brand, Sparks, MD) for the cutaneous tissue. Implanted mice were monitored daily for comfort, survival, and weight. Ten biopsy samples from 10 different patients were used. Each sample was used to inoculate one control mouse (treated with PBS) and one mouse treated with one of the shIL1R2 doses.

\section{Treatment of Mice with shIL1R2 and Quantification of Lesions}

Twelve days after tissue injection, animals received a daily intraperitoneal injection of $100 \mu \mathrm{L}$ of sterile PBS solution (control group, $n=10$ ) or containing 5 or 25 $\mu \mathrm{g} / \mathrm{kg}$ shlL1R2 ( $n=5$ for each group) (R\&D Systems, Inc., Minneapolis, MN) and were monitored for survival and weight. Two weeks later, mice were anesthetized with isoflurane $/ \mathrm{O}_{2}$ mixture, then euthanized in an atmosphere saturated by $\mathrm{CO}_{2}(10 \mathrm{~L} / \mathrm{min})$, and the abdominal cavity was examined under a fluorescence stereomicroscope connected to a color CCD HD camera (DAGE-MTI, Michigan City, IN). A detectable signal depends on the brightness of the fluorophore and tissue penetration of both the excitation and emission light. Fluorescence of CFDA SE was detected at $\chi$ ex465/ $\chi$ em535. ${ }^{26}$ Using these excitation/emission wavelengths and fluorescence filters, labeled tissue was detected without noticeable tissue autofluoresecence or background noise. Lesions (Figure 1, C and D) were numbered, measured, and photographed in situ before being collected and stored at $-80^{\circ} \mathrm{C}$ for histological studies using H\&E staining, CD10, and cytokeratin immunostaining, and quantitative realtime (qPCR) analyses.

\section{Vimentin and Cytokeratin Immunostaining}

Tissue cryosections $(5 \mu \mathrm{m})$ were rinsed in cold PBS, treated with $3 \%$ hydrogen peroxide to block endogenous peroxidase activity, and incubated for 1 hour at room temperature with rabbit polyclonal anti-human cytokera- 

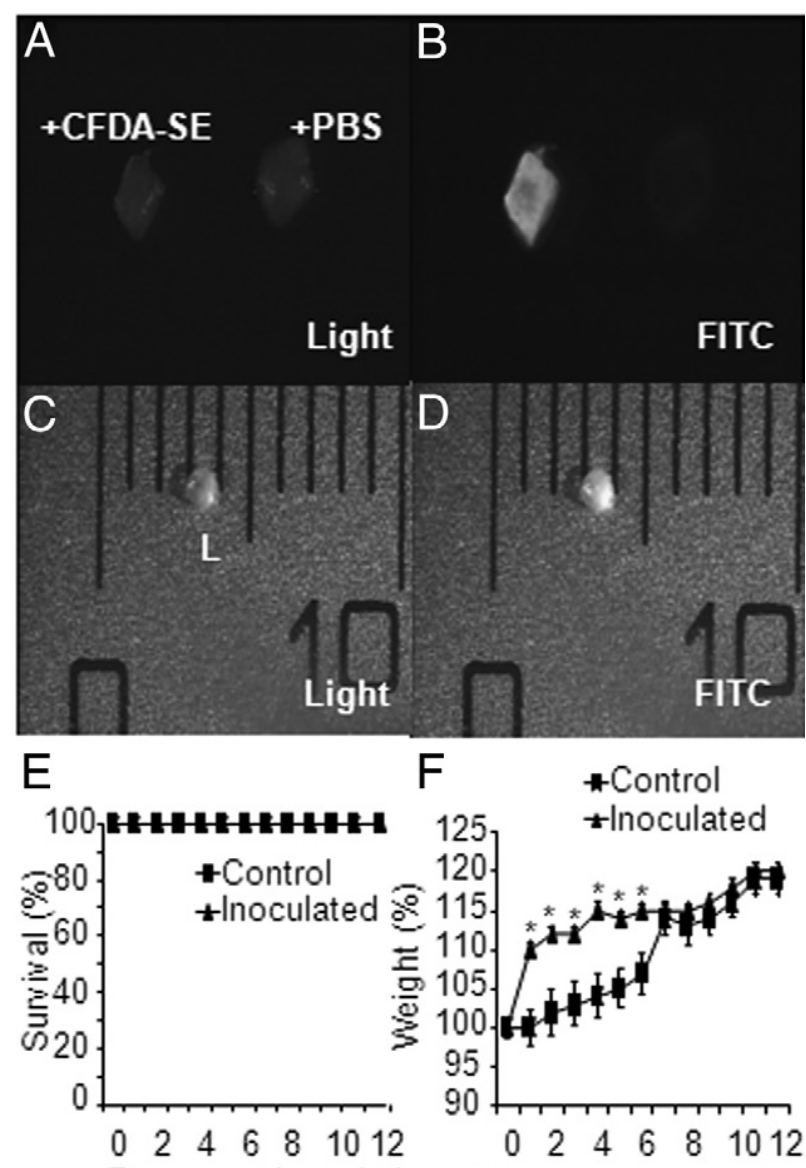

Days post-inoculation Days post-inoculation

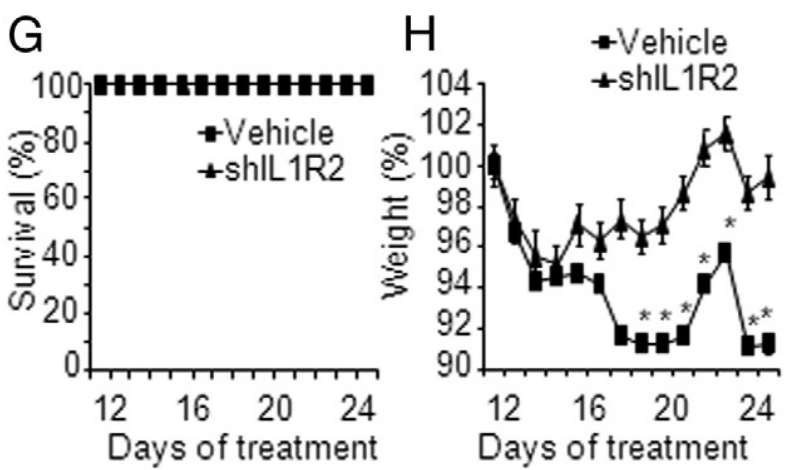

Figure 1. Staining of biopsy samples with CFDA-SE on day 0 (A and $\mathbf{B}$ ), fluorescent lesion after 26 days postinoculation $(\mathbf{C}$ and $\mathbf{D})$, and effect of endometrial tissue inoculation and treatment with shIL1R2 on the survival rate $(\mathbf{E}$ and $\mathbf{G})$ and body weight $(\mathbf{F}$ and $\mathbf{H})$ of animals. Figure summarizes results obtained from 10 control mice and five mice treated with 5 or 25 $\mu \mathrm{g} / \mathrm{kg}$ shIL1R2. ${ }^{*} P<0.05$ as compared with control group.

tin 7 antibody (GeneTex, Irvine, CA) [1:100 dilution in PBS/bovine serum albumin (BSA) 3\%] and anti-human vimentin (Novus Biologicals, Littleton, CO) (1:100 dilution in PBS/BSA 3\%). Sections were then incubated with a peroxidase-conjugated goat anti-rabbit antibody (1:500 dilution in PBS/BSA 3\%) (Jackson ImmunoResearch Laboratories, Mississauga, ON, Canada) before being incubated with the peroxidase substrate 3,3'-diaminobenzidine for 5 minutes, rinsed in PBS, counterstained with hematoxylin, and mounted in Mowiol.

\section{RNA Extraction and qPCR}

RNA was extracted with Trizol (Invitrogen), and gPCR was performed using an $\mathrm{ABI} 7000$ Thermal Cycler (Applied Biosystems, Foster City, CA). Each PCR reaction contained $2 \mu \mathrm{L}$ of reverse transcriptase product, $0.5 \mu \mathrm{L}$ of primer (final concentration, $0.1 \mathrm{~mm}$ ), $12.5 \mu \mathrm{L}$ of SYBR Green PCR Master Mix (Invitrogen) containing TaqDNA polymerase buffer, deoxynucleotide triphosphate mix, SYBR green I, $\mathrm{MgCl}_{2}$, and TaqDNA polymerase. Primers were designed with Primer Premier 5 software to cross intron-exon boundaries and specificity to human tissue was verified with Basic Local Alignment Search Tool (BLAST) (http://blast.ncbi.nlm.nih.gov/Blast.cgi) (Table 1). Samples were tested in duplicate, and, for each reaction, negative controls without RNA or reverse transcriptase, RNA from mouse tissue (negative control), and RNA from endometrial tissue (positive control) were added.

\section{Statistical Analysis}

Data related to the number and volume of lesions followed a nonparametric distribution and were analyzed using the $U$-test. Data related to the weight of mice and qPCR followed a Gaussian distribution and were analyzed using the Student's $t$-test (GraphPad Software, San Diego, CA). Differences were considered as statistically significant for $P<0.05$.

\section{Results}

Survival and Body Weight Recovery After Tissue Inoculation and Treatment with shIL1R2

To first ascertain the effect of tissue inoculation before any treatment and that of shIL1R2 on animal health, we monitored animal body weight and survival rate. As shown in Figure 1, E and F, all inoculated animals survived, but had a higher weight during the first 7 days after inoculation $(P<0.05)$. However, no weight difference between inoculated and control mice was then observed until day 12, corresponding to the start of treatment. Similarly, all animals survived after daily injection of shIL1R2 $(25 \mu \mathrm{g} / \mathrm{kg})$ for 2 weeks or an equal volume of a vehicle solution (PBS) (Figure 1G). However, animals in both groups showed a slight weight loss during the first 3 days, which, in control mice, reached $91.3 \% \pm 0.5 \%$ at the end of treatment but was fully recovered $(99.4 \% \pm$ $0.8 \%$ ) in shIL1R2-treated mice (Figure $1 \mathrm{H}$ ).

\section{Endometrial Implants Preserve Typical Endometrial Histomorphology}

Endometrial tissue was allowed to implant and establish before starting treatment. Histological assessment of implants showed a well-preserved typical endometrial histomorphology comparable to initial endometrial tissue, with stroma surrounding glandular structures and distinguishable from the underneath murine host tissue (Figure 2, $A$ and $B$ ). 
1200 Khoufache et al

AJP October 2012, Vol. 181, No. 4

Table 1. List of PCR Primers

\begin{tabular}{|c|c|c|c|}
\hline Gene & Primers & $\operatorname{Tm}\left({ }^{\circ} \mathrm{C}\right)$ & GenBank accession no. \\
\hline Bax & 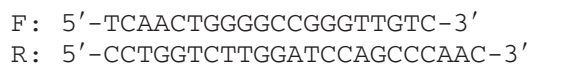 & 60 & NM_004324.3 \\
\hline Bcl2 & $\begin{array}{l}\mathrm{F}: \\
\mathrm{R}:\end{array}$ & 60 & NM_000657.2 \\
\hline GAPDH & $\begin{array}{l}\mathrm{F}: \quad 5^{\prime} \text {-CAGGGCTGCTTTTAACTCTGG-3' } \\
\mathrm{R}: \text { 5'-TGGGTGGAATCATATTGGAACA-3' }^{\prime}\end{array}$ & 60 & NM_002046.3 \\
\hline Integrin $\alpha v$ & 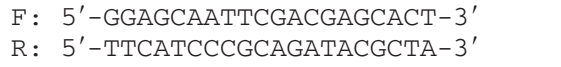 & 60 & NM_001144999.1 \\
\hline Integrin $\beta 3$ & $\begin{array}{l}\mathrm{F}: \text { 5'-TGACGAAAATACCTGCAACCG-3' }^{\prime} \\
\mathrm{R}:\end{array}$ & 60 & NM_000212.2 \\
\hline MMP2 & 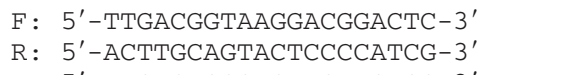 & 60 & NM_001127891.1 \\
\hline MMP9 & 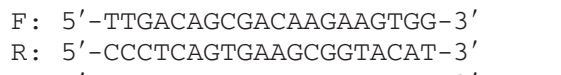 & 60 & NM_004994.2 \\
\hline TIMP1 & $\begin{array}{ll}\mathrm{F}: & 5^{\prime} \text {-AAGGCTCTGAAAAGGGCTTC-3' } \\
\mathrm{R}: & 5^{\prime} \text {-GAAAGATGGGAGTGGGAACA-3' }\end{array}$ & 60 & NM_003254.2 \\
\hline TIMP2 & $\begin{array}{ll}\mathrm{F}: & 5^{\prime} \text {-GAGAAGGAAGTGGACTCTGGAAAC-3' } \\
\mathrm{R}: & 5^{\prime} \text {-AAACTCTATATCCTTCTCAGGCC-3' }\end{array}$ & 56 & NM_003255.4 \\
\hline TIMP3 & 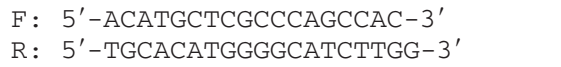 & 60 & NM_000362.4 \\
\hline VEGF & $\begin{array}{l}\mathrm{F}: 5^{\prime} \text {-GCTCTACCTCCACCATGCCA-3' } \\
\mathrm{R}: \quad 5^{\prime} \text {-CACCACTTCGTGATGATTCTGC-3' }\end{array}$ & 60 & NM_001171630.1 \\
\hline
\end{tabular}

$F$, forward; $R$, reverse.

\section{Treatment with shIL1R2 Reduces the Number and Volume of Endometrial Implants}

Using this in vivo endometriosis model with established endometrial implants, we next studied the impact of shIL1R2 treatment using two different doses ( 5 and 25 $\mu \mathrm{g} / \mathrm{kg}$ ). For each shIL1R2 dose, five mice versus five vehicle-treated mice (controls) were used. In other terms, there were 10 vehicle-treated animals and 5 mice per treatment. It is noteworthy that no significant difference between the control groups was observed, either in the

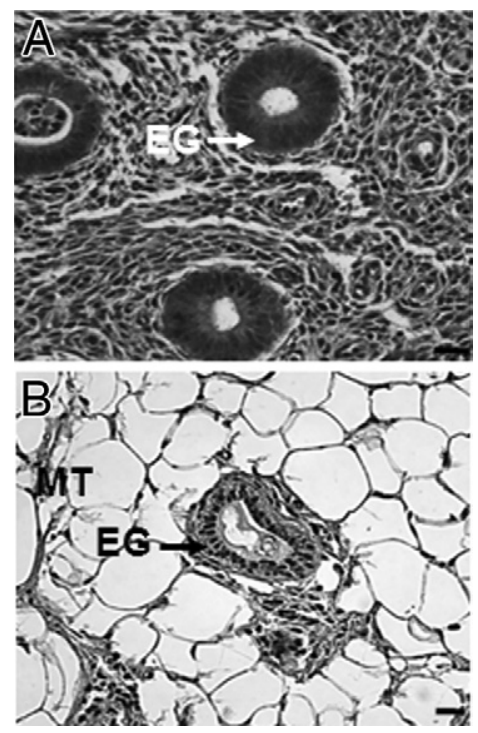

Figure 2. Histological examination of human endometrial implants in nude mice 2 weeks after tissue injection. Note the preserved stromal structure surrounding glands in endometrial implants (B), which is comparable to initial endometrial tissue (A) and distinguishable from murine tissue. H\&E staining. EG, endometrial gland; MT, mouse tissue. Scale bar $=20 \mu \mathrm{m}$. number (mean $\pm \mathrm{SD}, 8.0 \pm 4.84$ and $8.2 \pm 2.58$ ) or in the volume (mean $\pm \mathrm{SD}, 1.89 \pm 1.49$ and $1.31 \pm 0.82$ ) of endometriotic lesions $(P=0.84$ and $P=0.11$, respectively). Stereomicroscopic identification of fluorescencelabeled endometrial implants showed a recovery rate of $71.0 \% \pm 0.2 \%$. Lesions in shIL1R2-treated mice exhibited an obvious decrease in size as compared with control mice (Figure 3A). Statistical analysis showed that shlL1R2 (5 and $25 \mu \mathrm{g} / \mathrm{kg}$ ) exerts a significant inhibitory effect on the development of endometrial implants by decreasing their number $(P<0.05)$ and total volume (6.6- and 4.8-fold reduction, respectively) $(P<0.001)$ (Figure $3, \mathrm{~B}$ and $\mathrm{C}$ ). Histological evaluation further showed disrupted structures in lesions from shIL1R2treated mice, as compared with lesions from vehicletreated control mice showing well-defined endometrial glands and stroma surrounded by host mouse tissue (Figure 4, A and B). Immunostaining of vimentin and cytokeratins confirmed the presence of endometrial stromal and glandular cells, respectively (Figure 4, C and E).

\section{shlL1R2 Limits Endometrial Tissue Invasiveness and Dissemination}

Analysis of harvested lesions according to the implantation site showed several invaded organs and tissues in control mice, mainly the intestines, the peritoneum, the liver, and fat tissue, whereas shILR2 treatment appeared to increase the resistance of many organs to invasion by human endometrial implants (Figure 5, A-C). Statistical analysis showed that in mice treated with shIL1R2 (5 and $25 \mu \mathrm{g} / \mathrm{kg}$ ), lesion size and number were significantly reduced in these organs and tissues. Furthermore, lesions fully disappeared in the uterus and ovaries (Figure 5, D-I). 
A

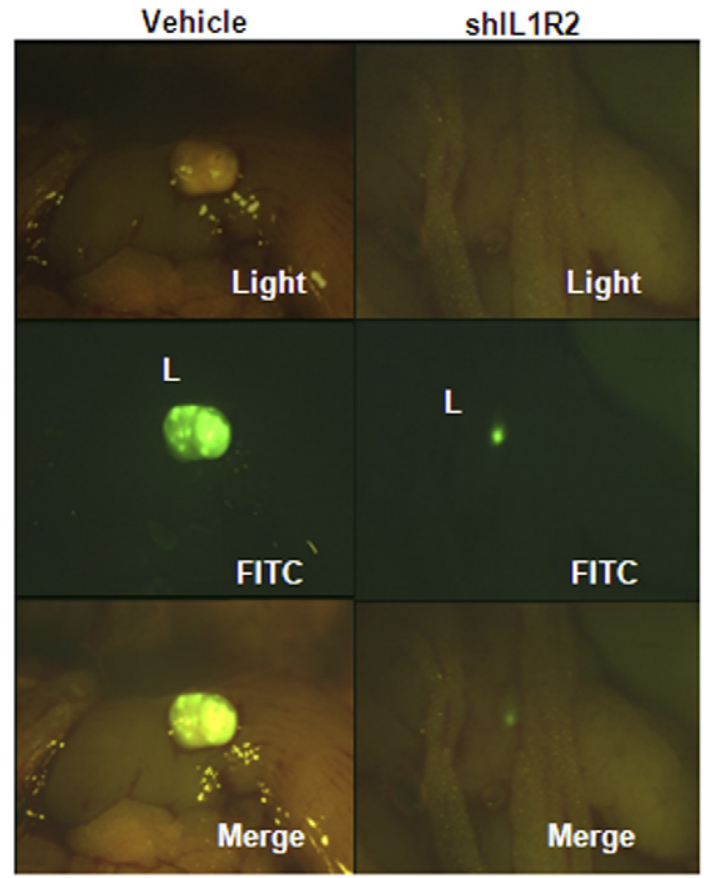

B

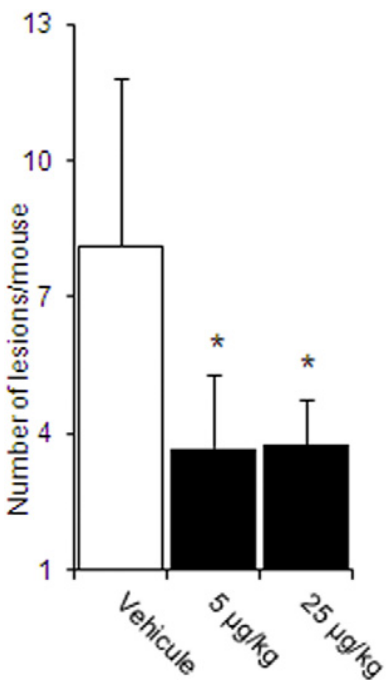

C

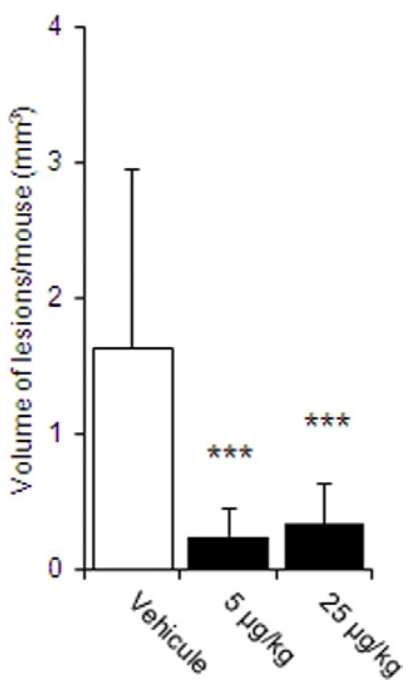

Figure 3. Effect of shIL1R2 treatment on number and volume of endometrial lesions. Endometrial implants were observed at sacrifice by fluorescence stereomicroscopy (A) in mice treated with vehicle (left) or shIL1R2 $(5 \mu \mathrm{g} / \mathrm{kg})($ right) Implants as observed by optic light (upper) or epi-fluorescence (middle) Merged images are shown (lower). Number (B) and volume (C) of implants were determined in situ. Figure summarizes results obtained from control ( $n=$ $10)$ and shIL1R2-treated mice ( $n=5$ for each sIL1R2 dose). Bars represent mean $\pm \mathrm{SD} .{ }^{*} P<0.05$ and ${ }^{* * * *} P<0.001$, as compared with control group.

\section{Impact of shIL1R2 Treatment on Adhesion, Survival, Invasion, and Angiogenesis Factors}

The development of endometriosis requires an intricate network of biological processes, including cell adhesion, invasion and angiogenesis, which enable endometrial tissue to implant and grow within the host tissue, as well as the deployment of anti-apoptotic mechanisms that favor its ectopic survival. To investigate whether any significant changes in these biological processes may underlie the shlL1R2-induced diminution in the number, size, and dis- semination of endometrial implants, the expression of main tissue adhesion, apoptosis, proteolysis, and angiogenesis mediators found to be significantly dysregulated in human endometriotic lesions was assessed.

As shown in Figure 6, A and B, treatment with shIL1R2 (5 and $25 \mu \mathrm{g} / \mathrm{kg}$ ) led to a significant and dose-dependent down-regulation of the adhesion receptors integrins $\alpha \mathrm{V}$ $(P<0.05$ and $P<0.001$, respectively) and $\beta 3(P<0.05)$ in endometrial implants. We then investigated the expression of $\mathrm{Bax}$ and $\mathrm{Bcl}-2$, which are two main regulatory proteins of cell apoptosis and survival, respectively. For Bax expression, no statistically significant difference between control lesions and those collected from mice treated with $5 \mu \mathrm{g} / \mathrm{kg}$ shlL1R2 was noted. However, at a higher shlL1R2 dose $(25 \mu \mathrm{g} / \mathrm{kg})$, Bax expression was significantly decreased $(P<0.01)$ (Figure $6 \mathrm{C}$ ). As for Bclll, the inhibitory effect of shIL1R2 was dose dependent and statistically significant at both shIL1R2 doses $(P<0.001)$ (Figure 6D)

Matrix metalloproteinases play a critical role in the invasive capacity of endometrial implants and the deployment of a new vessel network. Therefore, we analyzed the expression level of MMP-2 and MMP-9, two MMPs found to be up-regulated in active endometriotic lesions and involved in endometriosis development. ${ }^{27-30}$ The results showed a significant decrease in MMP-2 mRNA levels in mice treated with $5(P<0.01)$ and $25 \mu \mathrm{g} / \mathrm{kg}$ $(P<0.001)$ of shlL1R2, compared with control mice (Figure 7A). As for MMP-9 mRNA levels, we noted a significant diminution in endometriotic lesions collected from mice
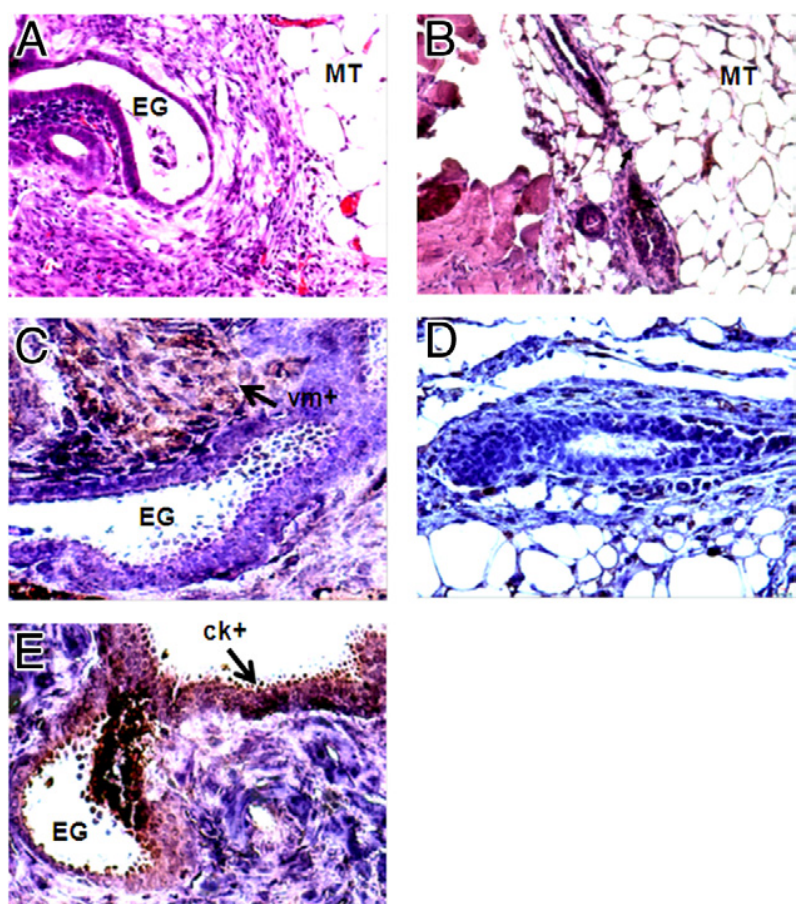

Figure 4. Histological evaluation of endometrial implants from mice treated with vehicle (A) or shIL1R2 $(\mathbf{B})$ at sacrifice (magnification, $\times 10$ ). Endometrial stromal and glandular cells were identified using vimentin (C) and cytokeratin (E) immunostaining. Sections incubated without the primary antibody were used as negative control for immunostaining (D) (original magnification, $\times 20$ ). ck + , cytokeratin-positive immunostaining; $E G$, endometrial gland; MT, mouse tissue; $v m+$, vimentin-positive immunostaining. 


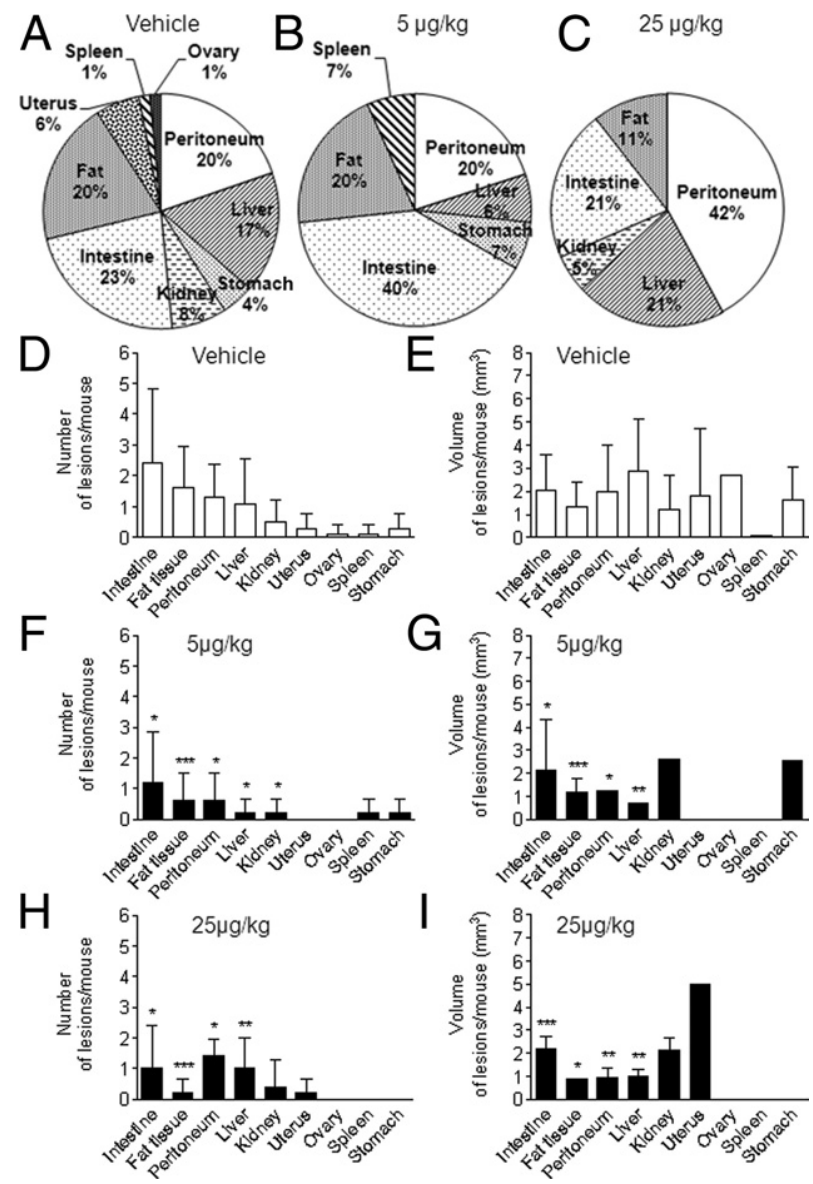

Figure 5. Effect of shIL1R2 on endometrial tissue invasiveness and dissemination. Endometrial implants were localized using fluorescence stereomicroscopy, then counted and measured in situ. Figure summarizes number $(\mathbf{A}-\mathbf{D}, \mathbf{F}$, and $\mathbf{H})$ and volume $(\mathbf{E}, \mathbf{G}$, and $\mathbf{I})$ of lesions per mouse according the implantation site after treatment with vehicle (control) or with 5 or $25 \mu \mathrm{g} / \mathrm{kg}$ shIL1R2. Results are from 10 control mice and five mice for each concentration of shIL1R2. Data are mean \pm SD. ${ }^{*} P<0.05,{ }^{* *} P<0.01$, and ${ }^{* * * *} P<0.001$, as compared with control group.

treated with $5(P<0.05)$ and $25 \mu \mathrm{g} / \mathrm{kg}(P<0.001)$ of shIL1R2 in comparison with control lesions (Figure 7B). Furthermore, as the invasive capacity of endometrial tissue depends on the balance between MMPs and their natural tissue inhibitor TIMPs, we further evaluated, in the same endometriotic lesions, the expression level of TIMPs 1, 2, and 3, known for inhibiting MMP-2 and MMP-9 activities. ${ }^{29,30}$ Data depicted in Figure 7, C-E, show that shILR2 had a significant dose-dependent impact on TIMP expression. Actually, treatment of mice with $5 \mu \mathrm{g} / \mathrm{kg}$ of shlL1R2 resulted in a significant up-regulation of TIMP1 $(P<0.05)$ and TIMP2 $(P<0.05)$ mRNA levels, as compared with vehicle-treated mice, whereas no statistically significant effect on TIMP3 mRNA levels was noted. However, treatment with $25 \mu \mathrm{g} / \mathrm{kg}$ of shlL1R2 rather had a down-regulatory effect on TIMPs 1, 2, and 3 expression $(P<0.01, P<0.01$ and $P<0.001$, respectively). Furthermore, treatment with shIL1R2 either at 5 or $25 \mu \mathrm{g} / \mathrm{kg}$ significantly inhibited the expression of vascular endothelial cell growth factor (VEGF), a major angiogenic factor markedly expressed in active, early-stage, and highly vascularized endometriotic lesions $^{31}(P<0.01)$ (Figure $\left.7 \mathrm{~F}\right)$.

\section{Discussion}

This report, for the first time, provides evidence that shIL1R2 can inhibit ectopic endometrial tissue growth and endometriosis progression in vivo. Using a nude mouse model of endometriosis, ${ }^{32,33}$ in which human endometrial tissue was allowed to implant and to establish before any exogenous treatment, our data show that administration of shIL1R2 significantly reduced the number, volume, and dissemination of endometrial implants. Our data also show that shIL1R2 down-regulates the expression of integrins $\alpha \mathrm{V}$ and $\beta 3$, MMPs 2 and 9, and VEGF and Bclll, which are major mediators of adhesion, angiogenesis, tissue remodeling, and cell survival and known to be significantly involved in endometriosis.

These findings are of relevance for endometriosis pathophysiology. The development of endometriotic lesions requires critical steps including attachment of endometrial cells to and invasion of the peritoneal surface, recruitment of inflammatory cells, induction of angiogenesis in the surrounding host tissue, and endometrial cell survival and proliferation.

Integrin receptors play an important role in cell adhesion to the extracellular matrix (ECM). Both $\alpha \mathrm{v}$ and $\beta 3$
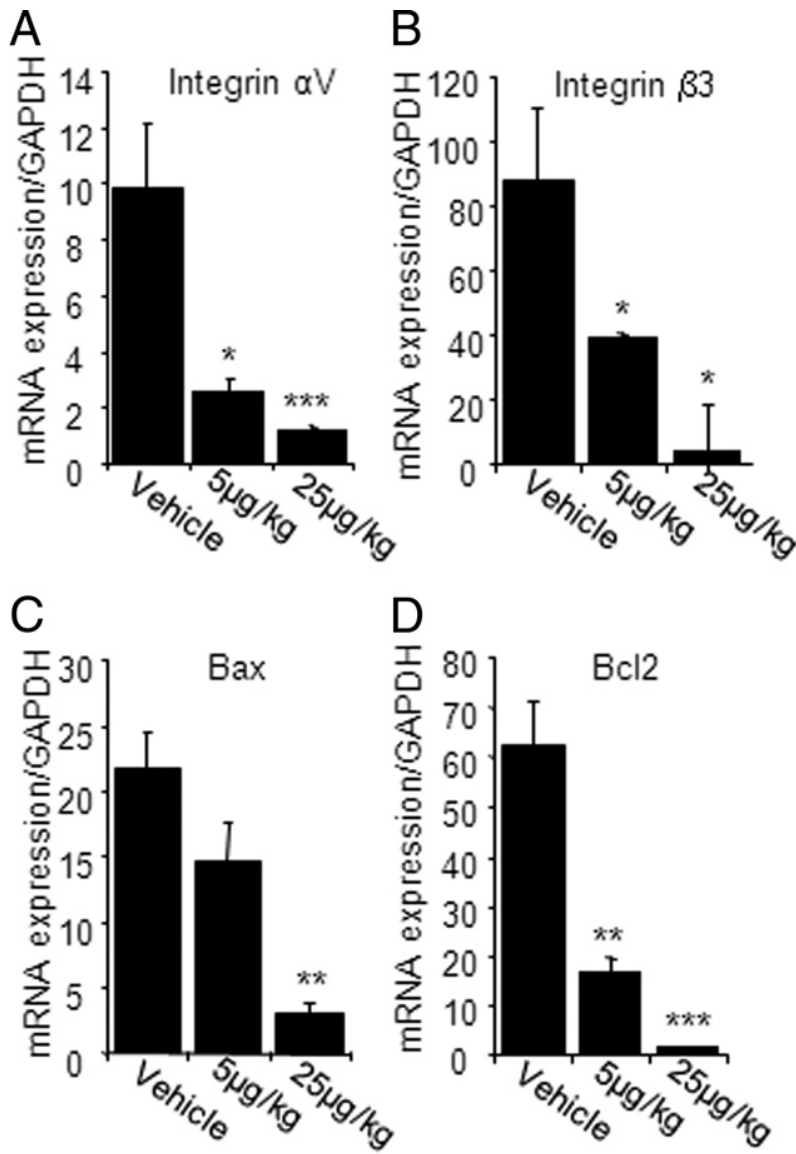

Figure 6. Real-time PCR analysis of the expression of integrin $\alpha \mathrm{V}$ (A) integrin $\beta 3$ (B), Bax (C), and BclII (D) in lesions harvested from mice treated with vehicle (control) or with 5 or $25 \mu \mathrm{g} / \mathrm{kg}$ shIL1R2. mRNA levels were normalized to that of the house-keeping gene GAPDH. Results were from 10 control mice and five mice for each concentration of shIL1R2. Data are mean \pm SEM. ${ }^{*} P<0.05$, ${ }^{* *} P<0.01$, and ${ }^{* * * *} P<0.001$, as compared with control group. 
A
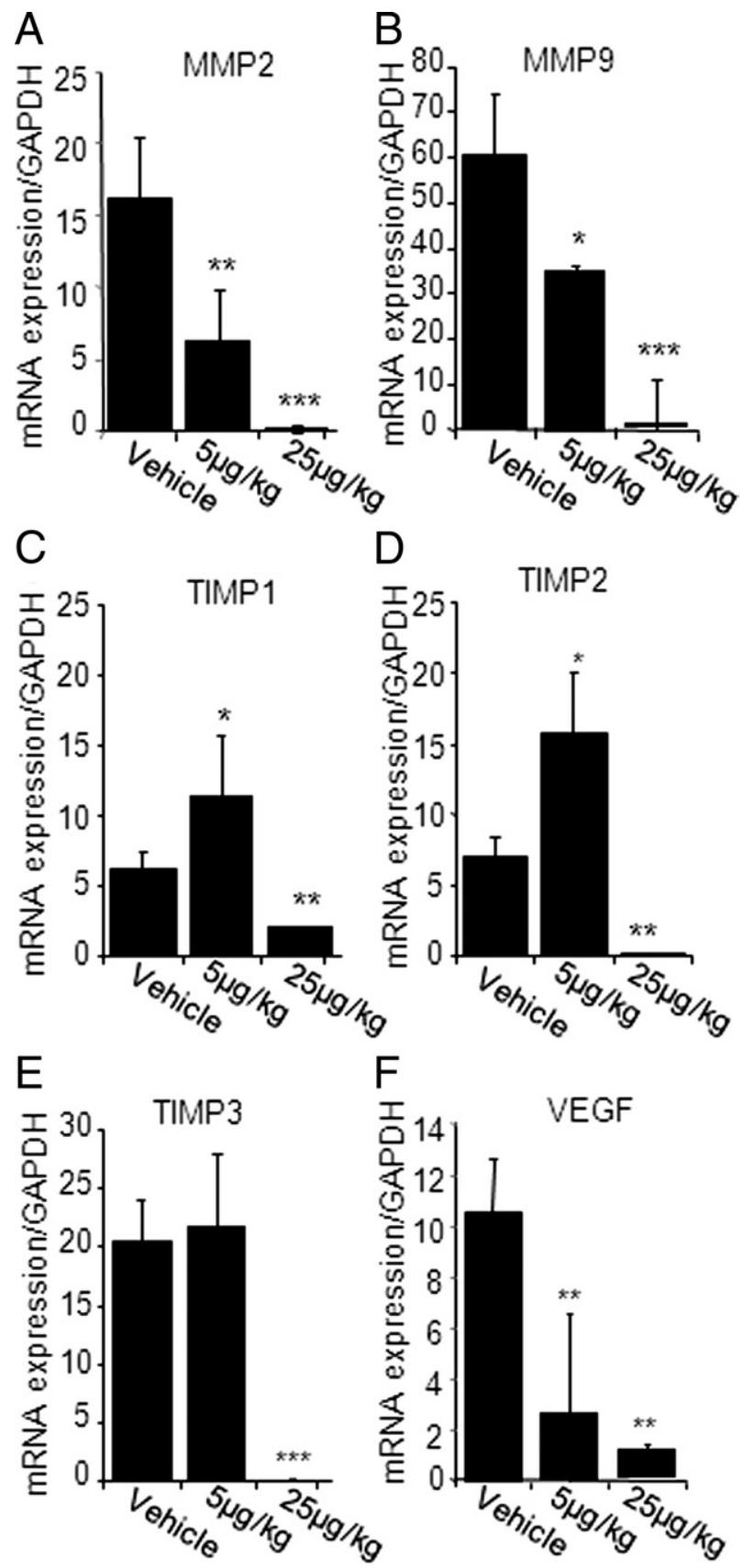

$\mathrm{F}$

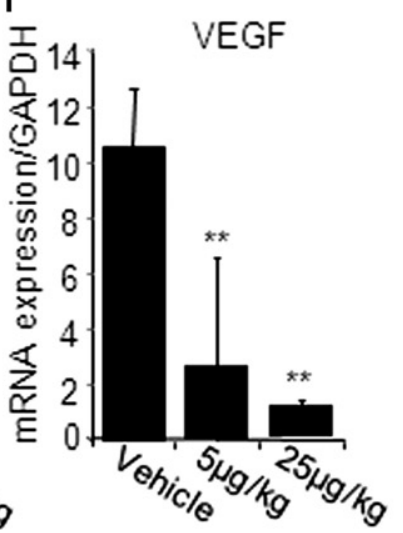

Figure 7. Real-time PCR analysis of the expression of MMP-2 (A), MMP-9 (B), TIMP1 (C), TIMP2 (D), TIMP3 (E), and VEGF (F) in lesions harvested from mice treated with vehicle (control) or with 5 or $25 \mu \mathrm{g} / \mathrm{kg}$ shIL1R2. mRNA levels were normalized to that of the house-keeping gene GAPDH. Results were from 10 control mice and five mice for each concentration of shIL1R2. Data are mean \pm SEM. ${ }^{*} P<0.05$, ${ }^{* * *} P<0.01$, and ${ }^{* * * *} P<0.001$, respectively, as compared with control group.

integrins, which are also markers of active neovascularization, ${ }^{34,35}$ show an increased expression in endometriotic stromal cells. ${ }^{36}$ Required for ECM degradation during tissue invasion ${ }^{10,37}$ and crucial for sprouting of capillaries from pre-existing vessels, MMPs were found to be overexpressed in active endometriotic lesions. ${ }^{27,29,30}$ This was also reported for VEGF, a key angiogenic factor, which, in addition, showed a high expression level in peritoneal macrophages of women with endometrio- sis. ${ }^{31,38}$ Such an active tissue remodeling and angiogenesis is coupled with the abnormal ability of endometrial tissue to proliferate and to resist apoptosis. This is supported by the detection of numerous alterations in the apoptotic pathways, including a significant up-regulation of the anti-apoptotic molecule Bclll and a significant down-regulation of the pro-apoptotic factor Bax. ${ }^{39}$ In this study, we have selected some key genes that were previously reported as being involved in endometriosis. These genes are representative only of the intricate network of changes occurring during endometriosis development, leading to abnormal angiogenesis, tissue remodeling, survival, and growth. Indeed, further studies will be required to assess in situ, for instance, the impact of shIL1R2 treatment on these processes.

The present study further showed that, although shIL1R2 treatment at $5 \mu \mathrm{g} / \mathrm{kg}$ had a down-regulatory effect on MMP-2 and MMP-9 expression levels, at the same time it displayed an up-regulatory effect on TIMP1 and TIMP2, MMP natural inhibitors. ${ }^{29,30}$ Furthermore, treatment with $5 \mu \mathrm{g} / \mathrm{kg}$ of shIL1R2 significantly downregulated the expression of Bclll, an anti-apoptotic molecule, but had no significant effect on Bax, which is endowed with anti-apoptotic properties. Indeed, assessment of apoptosis as well as MMP proteolytic activity will be required. In our model, endometrial implants were small, particularly those collected from mice treated with shIL1R2, and most of the lesions were used entirely for mRNA extraction. Tissue pooling will likely be necessary for the assessment of MMP proteolytic activity by zymography for instance and surgically induced endometriosis would provide a sufficient amount of tissue for quantitative analyses of expression and activity of proteins. However, our model is advantageous, as we introduced endometrial tissue into the peritoneal cavity of mice and allowed it to grow to mimic human peritoneal endometriosis development. Nevertheless, these results suggest that shIL1R2 treatment acts by altering the balance of pro- and anti-proteolysis molecules in endometriotic implants in the nude mice model and that of pro- and anti-apoptotic factors, which may contribute to the inhibition of endometrial tissue invasiveness, growth, and dissemination. Curiously, shIL1R2 effects were observed at $5 \mu \mathrm{g} / \mathrm{kg}$, whereas a higher dose $(25 \mu \mathrm{g} / \mathrm{kg})$ instead decreased TIMP2, TIMP3, and Bax mRNA levels. This suggests that shIL1R2 exerts a dose-dependent action in vivo, and that the lowest dose used is more appropriate to achieve the expected beneficial effects of shIL1R2 treatment in this experimental model of endometriosis. Endometriosis is an estrogen-dependent disease. However, it is increasingly evident that immuneinflammatory changes occurring within the peritoneal cavity, where endometriosis is essentially found and diagnosed, play a significant role in the major symptoms of disease and the capability of endometrial tissue to implant and to develop endometriosis. ${ }^{10,40} \mathrm{IL}-1$, a major proinflammatory and growth-mediating factor, may represent a key element of the local inflammatory network that develops in the peritoneal implantation site. IL-1 expression levels are increased in peritoneal macrophages and endometriotic lesions, and concentrations are elevated in the peritoneal 
fluid ${ }^{41-44}$ together with a concomitant diminution of the concentrations of its natural and potent inhibitor, sIL1R2. ${ }^{13,21,22}$ Such an imbalance in IL-1 counterregulatory mechanisms are also found in the eutopic endometrium and active endometriotic lesions..$^{22,45}$ Mainly secreted by activated monocytes/macrophages, IL-1 plays an important role in the recruitment and activation of proinflammatory cells, ${ }^{46}$ stimulates the adhesion of endometrial stromal cells, ${ }^{47-51}$ induces an angiogenic phenotype in ectopic endometrial cells, ${ }^{52}$ up-regulates MMP activity ${ }^{53}$, and promotes cell survival. ${ }^{54-56}$ This seems to be due in part to a decrease in the expression of IL1R2 22,55 and inhibition of apoptosis, particularly via the inhibition of $\mathrm{Bax}^{57}$ and the induction of antiapoptotic Bcl-2 family members. ${ }^{57,58}$

Nude mice are deficient in T and B cells, but still have the capability to mount a partial immune response because of functional natural killer cells and macrophages ${ }^{59}$ that may be activated by exogenous endometrial cells and that secrete IL-1. Previous studies showed that CD45-positive leukocytes are recruited into endometriotic lesions in nude mice and may be involved in ectopic endometrial tissue growth. ${ }^{60}$ Therefore, one could hypothesize that inhibition of IL-1-mediated leukocyte recruitment and activation may represent one of the possible mechanisms underlying shIL1R2 effects observed in our study. Nevertheless, further studies will also evaluate shIL1R2 effects with endometrial tissue from women with endometriosis, as it differs from normal endometrium.

shIL1R2 has been subject to preclinical studies ${ }^{61}$ and evaluated as a potential treatment of degenerative osteoarthritis in vivo. ${ }^{62}$ The therapeutic interest of this molecule was confirmed by Jäger et al, who reported a significant decrease in inflammatory osteoclast and odontoclast cell recruitment in rats. ${ }^{63}$ Therefore, our data demonstrate, for the first time, that shIL1R2 effectively interferes with the maintenance and growth of established endometriosis lesions and significantly reduces endometriotic lesion volume, size, and dissemination rate in vivo, and argues in favor of a potential therapeutic interest for this molecule. The current medical treatment of endometriosis, mainly based on the induction of a hypoestrogenic state, is associated with serious adverse effects and a high recurrence rate, and there is a crucial need for nonsteroidal therapeutic agents for more efficient and targeted treatment. Future pilot studies will be necessary to confirm these results in a nonhuman primate model for endometriosis, because of spontaneous endometriosis development, ${ }^{64}$ and ultimately in humans.

\section{Acknowledgments}

We thank Dr. Eric Gagné for helpful interpretation of histology and Dr. Mahera Al-Akoum, Nathalie Bourcier, Anne Loranger, and Carl Saint Pierre for technical assistance.

\section{References}

1. Giudice LC: Clinical practice. Endometriosis. N Engl J Med 2010, 362:2389-2398
2. Holoch KJ, Lessey BA: Endometriosis and infertility. Clin Obstet Gy necol 2010, 53:429-438

3. Cramer D, Wilson E, Stillman F, Berger M, Belisle S, Schiff I, Albrechts B, Gibsin M, Stadel B, Shoenbaum S: The relation of endometriosis to menstrual characteristics smoking and exercice. JAMA 1986, 255:19041908

4. Painter JN, Anderson CA, Nyholt DR, Macgregor S, Lin J, Lee SH, Lambert A, Zhao ZZ, Roseman F, Guo Q, Gordon SD, Wallace L, Henders AK, Visscher PM, Kraft P, Martin NG, Morris AP, Treloar SA, Kennedy SH, Missmer SA, Montgomery GW, Zondervan KT: Genome-wide association study identifies a locus at 7p15.2 associated with endometriosis. Nat Genet 2011, 43:51-54

5. Simpson JL, Elias S, Malinak LR, Buttram VC, Jr.: Heritable aspects of endometriosis. I. Genetic studies. Am J Obstet Gynecol 1980, 137: 327-331

6. Rier SE, Martin DC, Bowman RE, Dmowski WP, Becker JL: Endometriosis in rhesus monkeys (Macaca mulatta) following chronic exposure to 2,3,7,8-tetrachlorodibenzo-p-dioxin. Fundam Appl Toxicol 1993, 21:433-441

7. Anger DL, Foster WG: The link between environmental toxicant exposure and endometriosis. Front Biosci 2008, 13:1578-1593

8. Zeitoun KM, Bulun SE: Aromatase: a key molecule in the pathophysiology of endometriosis and a therapeutic target. Fertil Steril 1999, 72:961-969

9. Cakmak H, Guzeloglu-Kayisli O, Kayisli UA, Arici A: Immune-endocrine interactions in endometriosis. Front Biosci 2009, 1:429-443

10. Bondza PK, Maheux R, Akoum A: Insights into endometriosis-associated endometrial dysfunctions: a review. Front Biosci 2009, 1:415-428

11. Sampson JA: Metastatic or embolic endometriosis, due to the menstrual dissemination of endometrial tissue into the venous circulation. Am J Pathol 1927, 3:93-110143

12. Akoum A, Lemay A, Brunet C, Hebert J: Secretion of monocyte chemotactic protein-1 by cytokine-stimulated endometrial cells of women with endometriosis. Le Groupe d'Investigation en Gynecologie. Fertil Steril 1995, 63:322-328

13. Akoum A, Al-Akoum M, Lemay A, Maheux R, Leboeuf M: Imbalance in the peritoneal levels of interleukin 1 and its decoy inhibitory receptor type II in endometriosis women with infertility and pelvic pain. Fertil Steril 2008, 89:1618-1624

14. Akoum A, Lemay A, McColl S, Turcot-Lemay L, Maheux R: Elevated concentration and biologic activity of monocyte chemotactic protein-1 in the peritoneal fluid of patients with endometriosis. Fertil Steril 1996, 66:17-23

15. Kats R, Collette T, Metz CN, Akoum A: Marked elevation of macrophage migration inhibitory factor in the peritoneal fluid of women with endometriosis. Fertil Steril 2002, 78:69-76

16. Keenan JA, Chen TT, Chadwell NL, Torry DS, Caudle MR: IL-1 beta TNF-alpha, and IL-2 in peritoneal fluid and macrophage-conditioned media of women with endometriosis. Am J Reprod Immunol 1995, 34:381-385

17. Mori H, Sawairi M, Nakagawa M, Itoh N, Wada K, Tamaya T: Peritoneal fluid interleukin-1 beta and tumor necrosis factor in patients with benign gynecologic disease. Am J Reprod Immunol 1991, 26:62-67

18. Orlando S, Sironi M, Bianchi G, Drummond AH, Boraschi D, Yabes D, Mantovani A: Role of metalloproteases in the release of the IL-1 type II decoy receptor. J Biol Chem 1997, 272:31764-31769

19. Colotta F, Dower SK, Sims JE, Mantovani A: The type II 'decoy' receptor: a novel regulatory pathway for interleukin 1 . Immunol Today 1994, 15:562-566

20. Bossu P, Visconti U, Ruggiero P, Macchia G, Muda M, Bertini R, Bizzarri C, Colagrande A, Sabbatini V, Maurizi G, Del Grosso E, Tagliabue A, Boraschi D: Transfected type II interleukin-1 receptor impairs responsiveness of human keratinocytes to interleukin-1. Am J Pathol 1995, 147:1852-1861

21. Kondera-Anasz Z, Sikora J, Mielczarek-Palacz A, Jonca M: Concentrations of interleukin (IL)-1alpha. IL-1 soluble receptor type II (IL-1 sRII) and IL-1 receptor antagonist (IL-1 Ra) in the peritoneal fluid and serum of infertile women with endometriosis. Eur J Obstet Gynecol Reprod Biol 2005, 123:198-203

22. Akoum A, Lawson C, Herrmann-Lavoie C, Maheux R: Imbalance in the expression of the activating type I and the inhibitory type II interleukin 1 receptors in endometriosis. Hum Reprod 2007, 22:14641473 
23. Lawson C, Bourcier N, Al-Akoum M, Maheux R, Naud F, Akoum A: Abnormal interleukin 1 receptor types I and II gene expression in eutopic and ectopic endometrial tissues of women with endometriosis. J Reprod Immunol 2008, 77:75-84

24. Noyes RW, Hertig AT, Rock J: Dating the endometrial biopsy. Am J Obstet Gynecol 1975, 122:262-263

25. Defrere S, Colette S, Lousse JC, Donnez J, Van Langendonckt A: Review: luminescence as a tool to assess pelvic endometriosis development in murine models. Reprod Sci 2009, 16:1117-1124

26. Defrere S, Van Langendonckt A, Gonzalez Ramos R, Jouret M, Mettlen M, Donnez J: Quantification of endometriotic lesions in a murine model by fluorimetric and morphometric analyses. Hum Reprod 2006, 21:810-817

27. Wenzl RJ, Heinzl H: Localization of matrix metalloproteinase-2 in uterine endometrium and ectopic implants. Gynecol Obstet Invest 1998, 45:253-257

28. Chung HW, Wen Y, Chun SH, Nezhat C, Woo BH, Lake Polan M: Matrix metalloproteinase-9 and tissue inhibitor of metalloproteinase-3 mRNA expression in ectopic and eutopic endometrium in women with endometriosis: a rationale for endometriotic invasiveness. Fertil Steril 2001, 75:152-159

29. Chung HW, Lee JY, Moon HS, Hur SE, Park MH, Wen Y, Polan ML: Matrix metalloproteinase-2, membranous type 1 matrix metalloproteinase, and tissue inhibitor of metalloproteinase-2 expression in ectopic and eutopic endometrium. Fertil Steril 2002, 78:787-795

30. Bellehumeur C, Collette T, Maheux R, Mailloux J, Villeneuve M, Akoum A: Increased soluble interleukin-1 receptor type II proteolysis in the endometrium of women with endometriosis. Hum Reprod 2005, 20:1177-1184

31. Donnez J, Smoes P, Gillerot S, Casanas-Roux F, Nisolle M: Vascular endothelial growth factor (VEGF) in endometriosis. Hum Reprod 1998, 13:1686-1690

32. Bruner-Tran KL, Eisenberg E, Yeaman GR, Anderson TA, McBean J, Osteen KG: Steroid and cytokine regulation of matrix metalloproteinase expression in endometriosis and the establishment of experimental endometriosis in nude mice. J Clin Endocrinol Metab 2002 87:4782-4791

33. Lousse JC, Defrere S, Van Langendonckt A, Gras J, Gonzalez-Ramos $\mathrm{R}$, Colette S, Donnez J: Iron storage is significantly increased in peritoneal macrophages of endometriosis patients and correlates with iron overload in peritoneal fluid. Fertil Steril 2009, 91:1668-1675

34. Hii LL, Rogers PA: Endometrial vascular and glandular expression of integrin alpha(v)beta3 in women with and without endometriosis. Hum Reprod 1998, 13:1030-1035

35. Brooks PC, Clark RA, Cheresh DA: Requirement of vascular integrin alpha $v$ beta 3 for angiogenesis. Science 1994, 264:569-571

36. Adachi M, Nasu K, Tsuno A, Yuge A, Kawano Y, Narahara H: Attachment to extracellular matrices is enhanced in human endometriotic stromal cells: a possible mechanism underlying the pathogenesis of endometriosis. Eur J Obstet Gynecol Reprod Biol 2011, 155:85-88

37. Osteen KG, Igarashi TM, Yeaman GR, Bruner-Tran KL: Steroid and cytokine regulation of matrix metalloproteinases and the pathophysiology of endometriosis. Gynecol Obstet Invest 2004, 57:53-54

38. McLaren J, Prentice A, Charnock-Jones DS, Millican SA, Muller KH, Sharkey AM, Smith SK: Vascular endothelial growth factor is produced by peritoneal fluid macrophages in endometriosis and is regulated by ovarian steroids. J Clin Invest 1996, 98:482-489

39. Harada T, Taniguchi F, Izawa M, Ohama Y, Takenaka Y, Tagashira Y, Ikeda A, Watanabe A, Iwabe T, Terakawa N: Apoptosis and endometriosis. Front Biosci 2007, 12:3140-3151

40. Taylor RN, Mueller MD: Anti-angiogenic treatment of endometriosis: biochemical aspects. Gynecol Obstet Invest 2004, 57:54-56

41. Fakih $H$, Baggett $B$, Holtz G, Tsang KY, Lee JC, Williamson $H O$ : Interleukin-1: a possible role in the infertility associated with endometriosis. Fertil Steril 1987, 47:213-217

42. Taketani Y, Kuo TM, Mizuno M: Comparison of cytokine levels and embryo toxicity in peritoneal fluid in infertile women with untreated or treated endometriosis. Am J Obstet Gynecol 1992, 167:265-270

43. Mori H, Sawairi M, Nakagawa M, Itoh N, Wada K, Tamaya T: Expression of interleukin-1 (IL-1) beta messenger ribonucleic acid (mRNA) and IL-1 receptor antagonist mRNA in peritoneal macrophages from patients with endometriosis. Fertil Steril 1992, 57:535-542

44. Bergqvist A, Bruse C, Carlberg M, Carlstrom K: Interleukin 1beta, interleukin-6, and tumor necrosis factor-alpha in endometriotic tissue and in endometrium. Fertil Steril 2001, 75:489-495

45. Akoum A, Jolicoeur C, Kharfi A, Aube M: Decreased expression of the decoy interleukin-1 receptor type II in human endometriosis. Am J Pathol 2001, 158:481-489

46. Sims JE, Smith DE: The IL-1 family: regulators of immunity. Nat Rev Immunol 2010, 10:89-102

47. Sillem M, Prifti S, Monga B, Arslic T, Runnebaum B: Integrin-mediated adhesion of uterine endometrial cells from endometriosis patients to extracellular matrix proteins is enhanced by tumor necrosis factor alpha (TNF alpha) and interleukin-1 (IL-1). Eur J Obstet Gynecol Reprod Biol 1999, 87:123-127

48. Akoum A, Lemay A, Paradis I, Rheault N, Maheux R: Secretion of interleukin- 6 by human endometriotic cells and regulation by proinflammatory cytokines and sex steroids. Hum Reprod 1996, 11:2269-2275

49. Akoum A, Lemay A, Brunet C, Hebert J: Cytokine-induced secretion of monocyte chemotactic protein-1 by human endometriotic cells in culture. The Groupe d'Investigation en Gynecologie. Am J Obstet Gynecol 1995, 172:594-600

50. Akoum A, Lawson C, McColl S, Villeneuve M: Ectopic endometrial cells express high concentrations of interleukin (IL)-8 in vivo regardless of the menstrual cycle phase and respond to oestradiol by up-regulating IL-1-induced IL-8 expression in vitro. Mol Hum Reprod 2001, 7:859-866

51. Akoum A, Lemay A, Maheux R: Estradiol and interleukin-1beta exert a synergistic stimulatory effect on the expression of the chemokine regulated upon activation, normal $T$ cell expressed, and secreted in endometriotic cells. J Clin Endocrinol Metab 2002, 87:5785-5792

52. Lebovic DI, Bentzien F, Chao VA, Garrett EN, Meng YG, Taylor RN: Induction of an angiogenic phenotype in endometriotic stromal cell cultures by interleukin-1beta. Mol Hum Reprod 2000, 6:269-275

53. Sillem M, Prifti S, Koch A, Neher M, Jauckus J, Runnebaum B: Regulation of matrix metalloproteinases and their inhibitors in uterine endometrial cells of patients with and without endometriosis. Eur $\mathrm{J}$ Obstet Gynecol Reprod Biol 2001, 95:167-174

54. Watson RW, Rotstein OD, Parodo J, Bitar R, Marshall JC: The IL-1 beta-converting enzyme (caspase-1) inhibits apoptosis of inflammatory neutrophils through activation of IL-1 beta. J Immunol 1998, 161:957-962

55. Sunyer T, Lewis J, Collin-Osdoby P, Osdoby P: Estrogen's boneprotective effects may involve differential IL-1 receptor regulation in human osteoclast-like cells. J Clin Invest 1999, 103:1409-1418

56. Prince LR, Allen L, Jones EC, Hellewell PG, Dower SK, Whyte MK, Sabroe I: The role of interleukin-1beta in direct and toll-like receptor 4-mediated neutrophil activation and survival. Am J Pathol 2004, 165:1819-1826

57. Simonart T, Van Vooren JP: Interleukin-1 beta increases the BCL-2/ BAX ratio in Kaposi's sarcoma cells. Cytokine 2002, 19:259-266

58. Kuhn K, Hashimoto S, Lotz M: IL-1 beta protects human chondrocytes from CD95-induced apoptosis. J Immunol 2000, 164:2233-2239

59. Budzynski W, Radzikowski C: Cytotoxic cells in immunodeficient athymic mice. Immunopharmacol Immunotoxicol 1994, 16:319-346

60. Kayisli UA, Berkkanoglu M, Zhang L, Kizilay G, Arici A: The broadspectrum chemokine inhibitor NR58-3.14.3 suppresses the implantation and survival of human endometrial implants in the nude mice endometriosis model. Reprod Sci 2007, 14:825-835

61. Adamson P: Therapeutic strategies targeting interleukin-1 in vascular inflammation. Drug Discov Today 2006, 3:367-373

62. Bessis N, Guery L, Mantovani A, Vecchi A, Sims JE, Fradelizi D, Boissier MC: The type II decoy receptor of IL-1 inhibits murine collagen-induced arthritis. Eur J Immunol 2000, 30:867-875

63. Jager A, Zhang D, Kawarizadeh A, Tolba R, Braumann B, Lossdorfer S, Gotz W: Soluble cytokine receptor treatment in experimental orthodontic tooth movement in the rat. Eur J Orthod 2005, 27:1-11

64. D'Hooghe TM, Kyama CM, Chai D, Fassbender A, Vodolazkaia A Bokor A, Mwenda JM: Nonhuman primate models for translational research in endometriosis. Reprod Sci 2009, 16:152-161 